\title{
Approaches to Thoracic and Lumbar Spine: Our 10 Years Review
}

\author{
Parthasarahi Datta,
}

Department of neurosurgery,Nil Ratan Sircar Medical College \& Hospital,Kolkata

\begin{abstract}
:
Background: Lesions of the Thoracic and lumbar spine (TL) are numerous. These lesions affect one or more columns (anterior, middle and posterior) of the spine and compress the spinal cords either from anterior and posterior, giving rise to the features of radiculo-myelopathy. These lesions can be approached either from the anterior or posterior aspect of the spine. We present our last 10 years experience regarding the comparison between two approaches. Methods: Retrospective analysis of records of all patients with thoracic and lumbar lesion treated in our hospital between January 2005 and June 2014 was performed. Over the last 10 years, we came across 186 patients of thoracic and lumbar lesion lesion who were operated either by anterior or posterior approach and were the focus of this study. Follow up ranged from 6 months to 7 years. Results: All the patients presented with neurological deficits. They were evaluated with investigation protocol of our hospital. Anterior approach was done in 38 cases $(\mathrm{n}=38)$ and posterior approach was done in 148 cases $(n=148)$. We compared between the two groups in terms of perioperative complications, recovery, persisting symptoms and mortality. Conclusion: Complete recovery is better in the posterior approach $(74.3 \%) \mathrm{v} / \mathrm{s} 52.6 \%)$ and morality is more in the anterior approach (7.9\% v/s $1.3 \%)$.
\end{abstract}

Keywords: Columns, radiculo-myelopathy, thoracic, lumbar

\section{Introduction:}

Royle1 in 1928 described anterior decompression of thoracic spine for scoliotic deformity. Hodgson and Stock2 later described that anterior decompressions were not associated with spinal stabilization and the patients suffered postoperative instability and deformity. Ventral instrumentation was done by Humphries and Hawk3 in 1958; Dwyer and coworkers4,5, Zielke and Colleagues6 in 1970. But these constructs were not rigid. In late 1970s, Dunn7,8 developed double rod, double screw construct. Since then, development has occurred in anterior construct design. The newer generation titanium constructs are MRI compatible and technically simple. The lesions / pathologies which were treated in our series include trauma, infection (TB), deformity (kyphosis, scoliosis etc), metastasis and osteoporosis. Our study was carried out i) to compare the outcome of patients undergoing surgery by anterior and posterior approaches and ii) to compare the technical aspects of anterior and posterior operation. Our literature search did not reveal any study comparing anterior and posterior approach in such multiple disease pathologies.

\section{Materials and Methods:}

This is a retrospective study conducted at a tertiary care neurosurgical centre. Patient records, operation notes, radiology and outpatient files were scrutinized to collect data. Between January 2005 and June 2014, we have managed 186 patients (age range from 3 years -65 years, M:F =2:1) with thoracic and lumbar pathologies via anterior or posterior approaches. Inclusion criteria for anterior approaches are: i. Significant anterior compression of the spinal cord \pm Kyphotic deformity. ii. Absence of thoracic or abdominal pathologies which hinder the transthoracic or retroperitoneal approaches iii. Anterior and middle column disruption Inclusion criteria for posterior approaches are i. Significant posterior compression of the spinal cord \pm Kyphotic deformity ii. Patient condition not permitting lengthy anterior procedure iii. Posterior column disruption. It is recommended that, if the posterior elements of spine are injured significantly, an anterior construct may be insufficient to resist flexion forces. Loss of posterior tension band may require supplementation with posterior stabilization. In our series, we have not done both anterior and posterior 
stabilization in the same patient due to financial constraints. Pathology: The most common pathology/lesion in our series was trauma (110) followed by tuberculosis (42)

Table 1: Pathology of thoracic and lumbar lesions $(\mathrm{n}=186)$

\begin{tabular}{|l|l|}
\hline Disease (Pathology) & Number \\
\hline Trauma & 110 \\
\hline Tuberculosis & 42 \\
\hline Deformity (Kyphosis/Scoliosis) & 24 \\
\hline Metastasis / Osteoporosis & 10 \\
\hline
\end{tabular}

Clinical feature: The most common presenting complaint was pain and tenderness in $158(85 \%)$ patients. The pain was localized dull aching or lancinating with radiation. Motor symptom was present in 110 (59\%) patients in the form of paraplegia, paraperesis or trunkal weakness. Bladder / bowel involvement was present in $83(45 \%)$ patients in the form of hesitancy, urinary retention, overflow incontinence, urge incontinence and constipation. Spinal deformity was present in 92 (49\%) patients in the form of kyphosis, gibbus, kypho-scoliosis (Fig 1). Sensory symptom was present in 41(22\%) patients in the form of complete or partial sensory loss, tingling, band like sensation, abnormal sensations like burning, walking on cotton wool etc.[Fig 1]
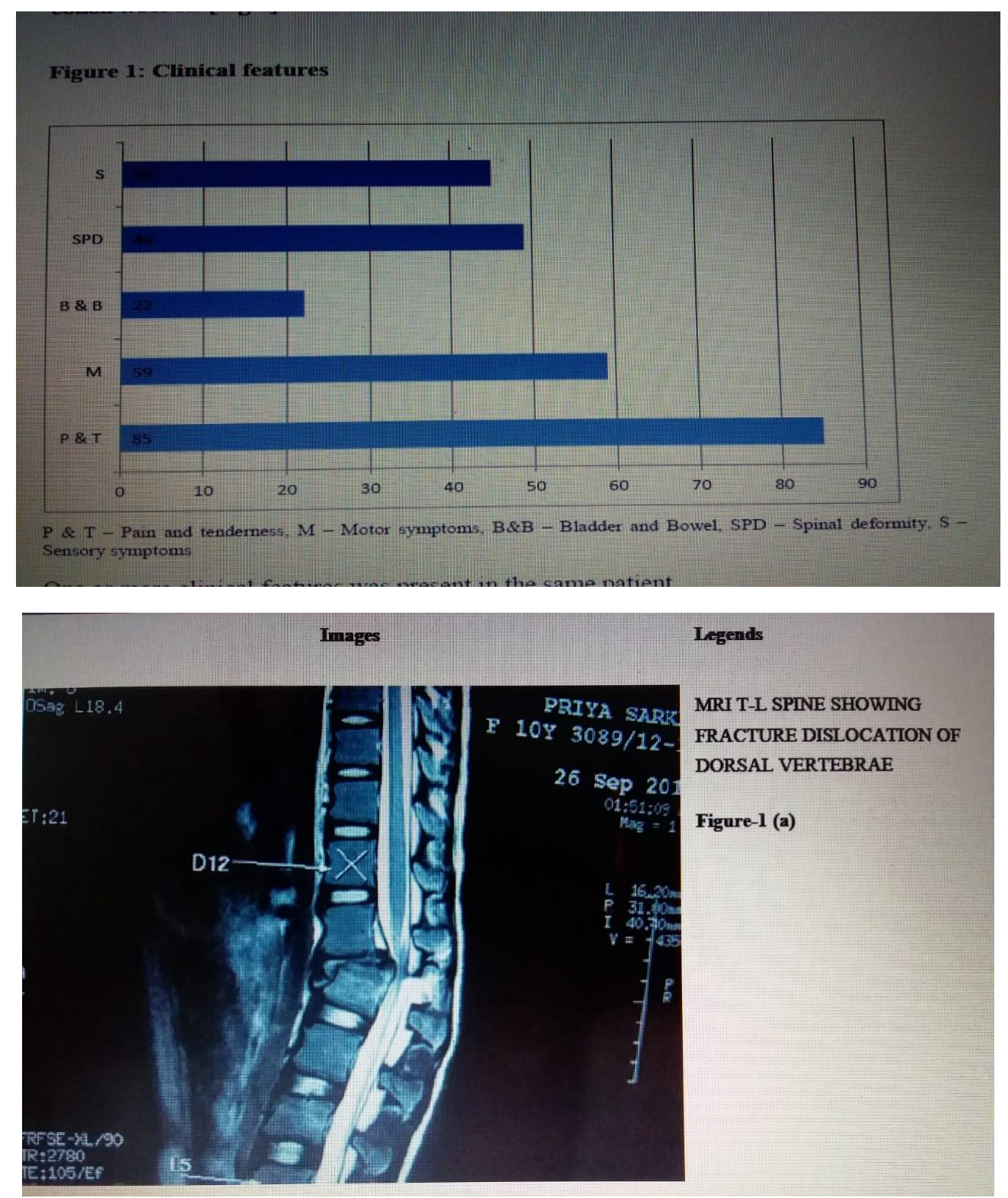


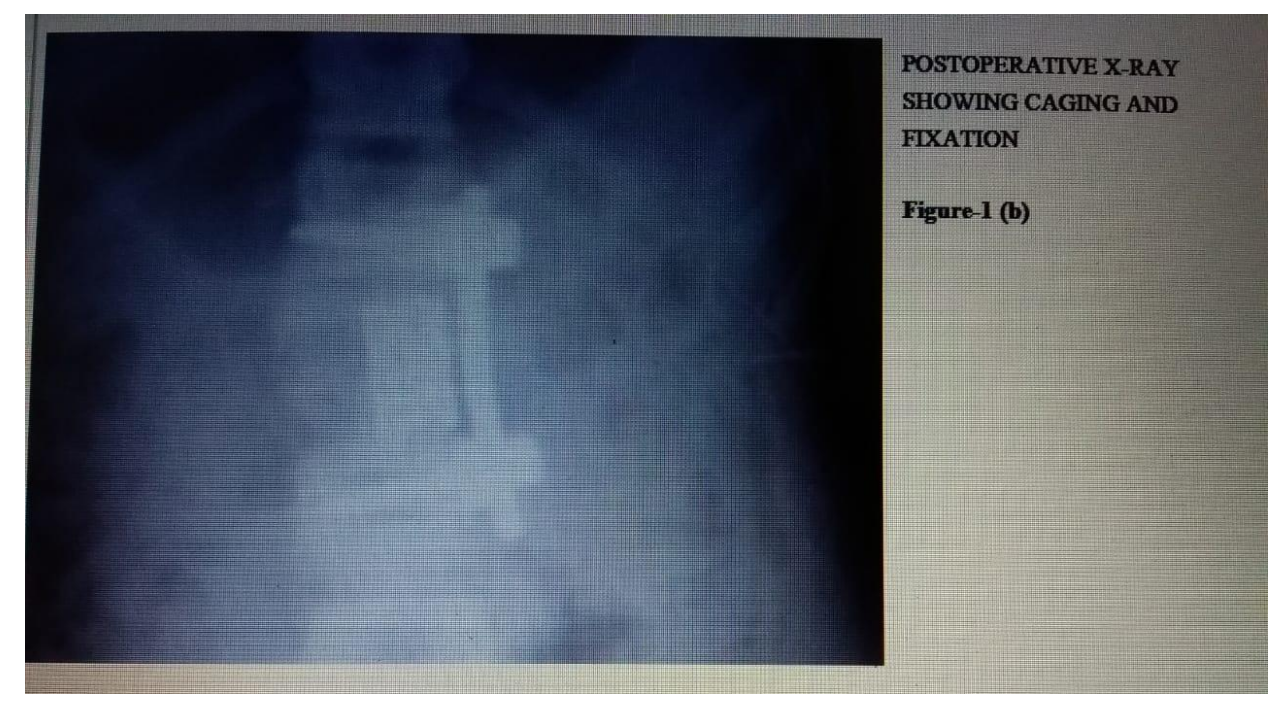

Fig 2: Radiological features Operative approaches: The approaches to thoracic and lumbar spine was either from anterior or posterior (Table 2).

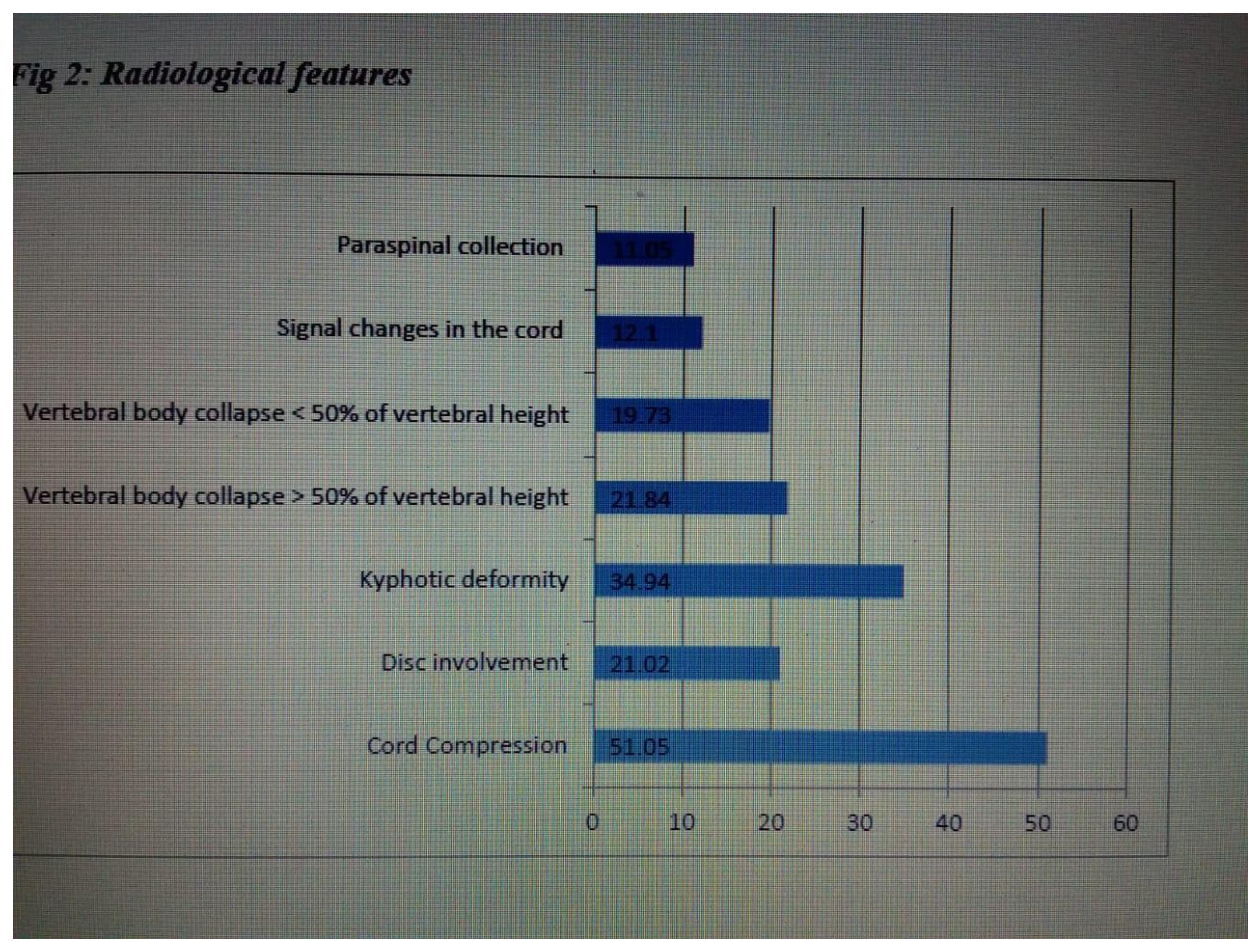

Table 2: Approaches to different disease pathology $(\mathrm{n}=186)$

\begin{tabular}{|c|l|}
\hline Type of operation & No (\%) \\
\hline 1. Anterior approach & \\
- Transthoracic transpleural & 32 \\
- Retroperitoneal & 5 \\
- Median stenotomy & 1 \\
\hline 2. Posterior approach & \\
- Transpedicular decompression + fixation & 140 \\
- Costo transversectomy & 4 \\
- Vertebroplasty & 3 \\
- Harrington rod & 1 \\
\hline
\end{tabular}


51.0521 .0234 .9421 .8419 .7312 .111 .050102030405060 Cord Compression Disc involvement Kyphotic deformity Vertebral body collapse $>50 \%$ of vertebral height Vertebral body collapse $<50 \%$ of vertebral height Signal changes in the cord Paraspinal collection Operative technique: Transpleural thoracotomy: Left sided approach is done for lesions below T4 vertebra and right sided approach is done for lesions above T4 vertebra. Double lumen tube intubation is done for upper thoracic interventions. Incision starts $4 \mathrm{~cm}$ from spinous $\rightarrow$ Lateral position with sand bag below the flanks process and extends to the mid axillary line over the rib which is 2 level above the area of Rib is transected starting from 1-2 cm lateral to the costo transverse joint up $\rightarrow$ pathology $\rightarrow$ chest retractor $\rightarrow$ Endothoracic fascia and parietal pleura incised $\rightarrow$ to the anterior part for exposure of $\rightarrow \mathrm{C}$-arm guidance for localization $\rightarrow$ prevertebral fascia $\rightarrow$ lung deflated adjacent discectomy $\rightarrow$ T-L junction, the lateral attachments of the diaphragm are incised upper and lower healthy vertebra are distracted $\rightarrow$ and corpectomy of involved vertebra wound closure. $\rightarrow$ chest drain $\rightarrow$ fixation $\rightarrow$ Titanium cage $\rightarrow$

\section{Results:}

The results of anterior and posterior approaches were analyzed in terms of outcome, complications and improvement of signs and symptoms. Statistical Analysis: Data collected were analyzed by software SPSS version 19 (Statistical Package for Social Scientists). Z-test and Chi-square tests were applied to find out the associations between different variables. A p value of less than 0.05 was considered to be significant. Complications: The complications of anterior and posterior approaches are depicted in

Table 3 Complications

\begin{tabular}{|l|l|l|}
\hline & Ant. Op (n=38) & Post. op (n=148) \\
\hline Wound infection & 4 & 25 \\
\hline $\begin{array}{l}\text { Persistent neurological } \\
\text { deficit }\end{array}$ & 8 & 10 \\
\hline $\begin{array}{l}\text { Worsened neurological } \\
\text { deficit }\end{array}$ & 1 & 2 \\
\hline $\begin{array}{l}\text { Persistent deformity } \\
\text { (kyphosis ) / symptoms }\end{array}$ & 10 & 20 \\
\hline $\begin{array}{l}\text { Chest complications } \\
\text { Postoperative and } \\
\text { hydrocephalus } \\
\text { tubercular meningitis }\end{array}$ & 2 & 5 \\
\hline $\begin{array}{l}\text { Injury to internal organs } \\
\text { like lungs, aorta, dura }\end{array}$ & 7 & 1 \\
\hline Lost to follow up & 5 & 20 \\
\hline Mortality & 3 & 30 \\
\hline
\end{tabular}

Persistent deformity / symptoms signifies that the patients in this group did not have complete recovery. The preoperative status (pain; bladder - bowel; motor and sensory symptoms; and deformity) was either partially or incompletely relived. The neurological function at presentation and at follow up was graded up using the Frankel classification. The spinal deformity (kyphosis, scoliosis) was graded by measuring cobb's angle in short term (immediately after operation) and long term (after five years). Pain and bladder bowel was graded by subjective experience of the patients. Mortality was due to pulmonary complications (pneumonia, atelectasis, pulmonary oedema, respiratory tract infection, prolonged ventilator support and its consequences), prolonged recumbancy (bed sores, DVT,) sepsis and urinary tract infection. Outcome: The outcome of anterior and posterior approach are depicted in table 4. 
Table 4: Outcome

\begin{tabular}{|l|l|l|l|}
\hline & $\begin{array}{l}\text { Anterior approach } \\
(\mathrm{n}=38)\end{array}$ & $\begin{array}{l}\text { Posterior approach } \\
(\mathrm{n}=148)\end{array}$ & $\mathrm{Z}$ and P values \\
\hline Complete recovery & $20(52.6)$ & $110(74.3)$ & $\mathrm{z}=2.40 \mathrm{p}=0.016^{* *}$ \\
\hline $\begin{array}{l}\text { Persisting deformity/ } \\
\text { symptoms }\end{array}$ & $10(26.3)$ & $20(13.5)$ & $\mathrm{z}=1.67 \mathrm{p}=0.096$ \\
\hline Complications & $16(42.1)$ & $53(37.8)$ & $\mathrm{z}=0.30 \mathrm{p}=0.765$ \\
\hline Mortality & $3(7.9)$ & $2(1.3)$ & $\mathrm{z}=2.60 \mathrm{p}=0.009^{* *}$ \\
\hline Lost to follow up & $2(5.3)$ & $30(20.3)$ & $\mathrm{z}=1.94 \mathrm{p}=0.052^{*}$ \\
\hline
\end{tabular}

Multiple outcome in some cases **

Significant difference between the two rates

Complete recovery was significantly higher in the posterior approach than the anterior approach (74.3\% vs. $52.6 \% ; \mathrm{p}=0.016)$. Mortality was significantly higher in anterior approach than in the posterior approach (7.9\% vs. $1.3 \%, \mathrm{P}=0.009)$ Improvement of signs and symptoms: Improvement of signs and symptoms in anterior and posterior approaches are depicted in table 5 and table 6.

Table 5: Improvement of signs and symptoms according to different approaches

\begin{tabular}{|l|l|l|l|l|l|l|l|l|}
\hline & \multicolumn{3}{|l}{ Anterior approach } & \multicolumn{3}{l|}{ Posterior approach } \\
\hline & Improved & $\%$ & $\begin{array}{l}\text { Not } \\
\text { improved }\end{array}$ & $\%$ & Improved & $\%$ & $\begin{array}{l}\text { Not } \\
\text { improved }\end{array}$ & $\%$ \\
\hline Pain and tenderness 158 & $30 / 38$ & 78.9 & $8 / 38$ & 21.9 & $90 / 120$ & 75 & $30 / 120$ & 25 \\
\hline Motor symptoms 110 & $22 / 30$ & 73.3 & $8 / 30$ & 26.7 & $60 / 80$ & 75 & $20 / 80$ & 25 \\
\hline Sensory symptoms 92 & $18 / 23$ & 78.26 & $5 / 23$ & 21.7 & $50 / 60$ & 83.3 & $10 / 60$ & 16.7 \\
\hline Spinal deformity 41 & $26 / 32$ & 81.2 & $6 / 32$ & 18.8 & $40 / 60$ & 66.7 & $20 / 60$ & 23.3 \\
\hline $\begin{array}{l}\text { Bladder/Bowel } \\
\text { involvement 83 }\end{array}$ & $6 / 11$ & 54.5 & $5 / 11$ & 45.5 & $20 / 30$ & 66.7 & $10 / 30$ & 33.3 \\
\hline
\end{tabular}

Pain and tenderness : X2 (1) $=0.25, \mathrm{p}=0.61$

Motor symptoms : X2 (1) $=0.03, \mathrm{p}=0.85$

Sensory symptoms : X2 (1) $=0.29, \mathrm{p}=0.59$

Spinal deformity : X2 (1) $=2.19, \mathrm{p}=0.138$.

Bladder / Bowel involvement: X2 (1) $=0.51, \mathrm{p}=0.475$

Thus improvement of signs and symptoms do not have a significant difference in anterior and posterior approaches.

Table 6: Short term and long term correction of spinal deformity by the two approaches

\begin{tabular}{|l|l|l|l|l|}
\hline Approach & Short term correction & \multicolumn{2}{l|}{ Long term correction } \\
\hline & Corrected & Not-corrected & Corrected & Not-corrected \\
\hline Anterior $(\mathrm{n}=32)$ & $28(87.5 \%)$ & $4(12.5 \%)$ & $26(81.2 \%)$ & $6(18.8 \%)$ \\
\hline Posterior $(\mathrm{n}-60)$ & $50(83.3 \%)$ & $10(16.7 \%)$ & $40(66.7 \%)$ & $20(33.3 \%)$ \\
\hline
\end{tabular}


Short term correction (immediately after operation) was not significantly different between the two approaches $[\mathrm{X} 2(1)=0.28, \mathrm{p}=0.59]$. Also long term correction (after 5 years) was not significantly different between the two approaches $[\mathrm{X} 2(1)=0.22, \mathrm{p}=0.14)]$.

\section{Discussion:}

Lesions of the T-L spine arte multiple and these lesions can be approached surgically either from anterior or posterior. The anterior and posterior approaches are of various types. In the present series we have analyzed the different lesions / pathologies of thoracic and lumbar spine, the surgical approaches, complications and outcome of different approaches. We have operated 186 patients (Anterior approach in 38 and posterior approach in 148) over a period of 10 years. After analyzing statistically we have found that i) complete recovery is better in the posterior approach, ii) mortality is higher in the anterior approach and iii) improvement of signs and symptoms including correction of spinal deformity in the short and long term do not have any statistical difference in the two approaches. We search the literature to see the results of different series when comparing anterior and posterior approaches. Bhabuk Garg et al9 analyzed 70 patients of T-L tuberculosis via anterior and / or posterior approaches and came to conclusion that i) kyphus correction is better in posterior instrumentation (72.8\% vs. 52.27\%) and ii) posterior approach has less mortality and complications. B Lin et al10 analysed 64 patients of T-L burst fractures by anterior and posterior approaches and came to conclusion that less intraoperative blood loss, complications, shorter operative time are the significant advantages of posterior surgery. Zhi-Wen Chen et all1 in their review of 36 patients of chronic T-L fractures, opined that hemothorax, abdominal distension and constipation were fewer in posterior approach; post operative pulmonary function and correction of kyphosis were better in posterior approach $(\mathrm{P}<0.05)$. Pinglin Yang et al12 operated on 291 patients of spinal tuberculosis in adult by either anterior or posterior approach and found similar outcomes in both approaches. Mark P Arts et al13 operated 56 patients by mini thoracotomy and 44 patients by transpendicular approach in thoracic disc herniations and came to conclusion that complication rate (pulmonary morbidity) was higher in transthoracic approach, neurological complications were same, large calcified paramedian herniated disc can be treated from posterior as well. Tarek Aly et al14 reviewed unstable T-L burst fractures by anterior and posterior approaches and concluded that operative time was shorter in posterior approach than anterior approach (median 171 minutes vs. 242 minutes), blood loss was smaller in posterior approach (median $550 \mathrm{ml}$ vs. $1120 \mathrm{ml}$ ), the average correction of kyphotic angle was larger in posterior group than anterior but not at final follow up ( $\mathrm{P}>0.050)$, the average loss of correction was also higher in the posterior group than in the anterior group $(\mathrm{P}>0.05)$. There was no significant difference in neurological outcome. M. Franic et al15 analysed anterior vs. posterior approaches in 3D correction of adolescent idiopathic thoracic scoliosis in 10 patients and concluded that both instrumentations provide similar reduction of frontal cobb angle, long term effects of correction of saggital cobb's angle is better by posterior approach, anterior approach was more effective in reduction of apical vertebral rotation. Metin Tuma et al16 operated 20 patients by posterior and 10 patients by anterior instrumentation in unstable T-L fractures and did not find any statistical difference in outcome. Gillet Philippe et al17 treated 22 patients by posterior and 15 patients by anterior approach in T-L fracture and concluded that the two procedures gave similar final results but an early surgery was necessary in the case of a posterior approach whereas correction remained possible after a greater delay with the anterior procedure. Marin F Stancic et al18 operated 13 patients by anterior and 12 patients by posterior approach in unstable T-L burst fractures and did not find any significant difference in terms of neurological improvement, economic or functional outcome. The operation time and blood loss was less in posterior approach. Gui Jun Xu et al19 operated 179 patients by anterior and 152 patients by posterior approach in T$\mathrm{L}$ burst fracture and found no difference in terms of neurological recovery, return to work, complications and cobbs angle correction. The anterior approach has longer operative time, greater blood loss and higher cost. WU Han et al20 operated 24 patients by anterior, 38 patients by posterior and 32 patients by paraspinal approach in T-L burst fracture and concluded that the anterior approach is convenient for resection of the vertebra and reconstruction of vertebral height but is more complicated and traumatic. The average operation time, blood loss, length of incision, post operative disability was lower in paraspinal / posterior approach. Curt Freudenberger et al21 operated 29 patients by anterior and 30 patients by posterior approach and opined that ALIF with anterior plating and PLIF with pedicle screw fixation had similar fusion and functional outcome, but ALIF group has significantly shorter surgical time and decreased blood loss. Mark A Ericson et al22 treated 85 patients by anterior and 39 patients by posterior approach in T-L idiopathic 
scoliosis and concluded that posterior procedure allows greater curve correction at the expense of more fused levels. Anterior procedure require significantly more operative time and have longer hospitalization. Ahmed Elsawaf et al23 analysed late outcomes in T-L fractures by anterior (30 patients) and posterior (30 patients) approaches and concluded that i) both groups have satisfactory outcome regarding pain relief and return to work ii) there is increase in postoperative kyphosis in the posterior group, which is secondarily due to inability of the posterior group to provide significant anterior column support. Alex Rabinovich et al treated 110 patients of adolescent idiopathic scoliosis and did not find any significant clinical difference between two groups. M Muschik et al24 operated 37 patients by anterior and 104 patients by posterior approach in idiopathic T-L scoliosis and concluded that balance of the spine is improved by the anterior technique, by posterior technique, however, it is declined. After analyzing our series and different other series we came to the conclusion that there are different merits and demerits of the anterior and posterior approach. We summarize the merits and demerits in table 6.

Table 7: Comparison between anterior and posterior approaches to thoracolumbar spine

\begin{tabular}{|c|c|c|}
\hline Approach & Merits & Demerits \\
\hline \multirow[t]{4}{*}{ Anterior } & Better resection of vertebra & More visceral and vascular injury \\
\hline & $\begin{array}{l}\text { Better decompression of anterior } \\
\text { compression }\end{array}$ & $\begin{array}{l}\text { Longer hospital stay } \\
\text { complicated than posterior }\end{array}$ \\
\hline & Better anterior support & Prolonged operation time \\
\hline & $\begin{array}{l}\text { Better correction of short segment } \\
\text { deformity }\end{array}$ & $\begin{array}{l}\text { More blood loss } \\
\text { Longer length of incision } \\
\text { Post operative chest and } \\
\text { abdominal complaints: } \\
\text { More Higher cost }\end{array}$ \\
\hline \multirow[t]{8}{*}{ Posterior } & Short operation time & Difficult to resect vertebra \\
\hline & Short hospital stay & $\begin{array}{l}\text { Difficult to give multi level } \\
\text { anterior support }\end{array}$ \\
\hline & Blood loss & \\
\hline & $\begin{array}{l}\text { less Postoperative chest and } \\
\text { abdominal complaints less }\end{array}$ & \\
\hline & Cost is less & \\
\hline & $\begin{array}{l}\text { Suitable in cases of other } \\
\text { pathologies in chest / abdomen }\end{array}$ & \\
\hline & $\begin{array}{l}\text { Suitable for decompressing } \\
\text { posterior compression }\end{array}$ & \\
\hline & $\begin{array}{l}\text { Suitable for long segment } \\
\text { deformity correction }\end{array}$ & \\
\hline
\end{tabular}

\section{Conclusion:}

In our series, posterior approach gives better complete recovery than anterior approach and anterior approach has greater mortality than posterior approach whereas improvement of signs and symptoms are comparable in the two approaches. But still in deciding regarding the approaches it is the surgeons familiarity with one approach, availability of thoracic or abdominal surgeons and comorbidities on the part of the patient are major determining factors.

References: 
[1] Royle ND. The operative removal of an accessory vertebra. Med J Aust 1: 467, 1928

[2] Hodgson A, Stock F. Anterior spinal fusion: A preliminary communication on radical treatment of Pott's disease and Pott's paraplegia. Br J Surg 44: 266-275 1956

[3] Humphries AW, Hawk WA: Anterior fusion of the lumbar spine using an internal fixative device. Surg Forum 9: 770-773, 1958

[4] Dwyer AF, Newton NC, Sherwood AA. Anterior approach to scoliosis. A preliminary report. Clin Orthop 62: 192-202, 1969

[5] Dwyer AF, Schafer MF. Anterior approach to scoliosis: Results of treatment in 51 cases. J Bone Joint Surg Br 56: 218-224, 1974

[6] Zielke K, Stunkat R, Beaujean F. Ventrale derotations- spondylodesis (German). Arch Orthop Unfallchir 85: 257-277, 1976

[7] Dunn HK. Anterior stabilization of thoracolumbar injuries. Clin Orthop 189: 116- 124, 1984

[8] Dunn HK. Anterior spine stabilization and decompression for thoraco lumbar injuries. Orthop Clin North Am. 17: 116-119, 1986

[9] Garg B, Kandwal P, Upendra BN, Goswami A. Anterior vs. posterior procedure for surgical treatment of thoracolumbar tuberculosis: A retrospective analysis. Indian J Orthop 46: 165-170, 2012

[10] Lin B, Chen ZW, Guo ZM, Liu H, Yi ZK. Anterior vs. posterior approach with subtotal corpectomy, decompression, and reconstruction of spine in the treatment of thoracolumbar burst fracture: A prospective randomized controlled study. J Spinal Disord Tech 2011 June

[11] Chen ZW, Ding ZQ, Zhai WL, Lian KJ, Kang LQ, Guo LX, Lui H, Lin B: Anterior vs. posterior approach in the treatment of chronic thoracolumbar fractures. Orthop 35: 219-224, 2012

[12] Yang P, He X, Li H, Zang Q, Yang B. Clinical efficacy of posterior and anterior instrumentation for the treatment of spinal tuberculosis in adults. Journal of Orthop. Surg and Research 9: 10, 2014

[13] Arts MP, Bartells RHMA. Anterior and posterior approach of thoracic disc herniation? A comparative cohort of mini thoracotomy vs. transpedicular discectomies. The Spine J. Sept. 2013

[14] Aly T, Sayed ME, E Wais W: Surgical management of unstable thoracolumbar burst fractures: Ant vs post surgery. J Spine and Neurosurgery. Oct 2013

[15] Franic M, Tilzac MK, Pozar M, Mimica M, PetrakJ, Ivankovic D, Pecina M. The J of Pain 98: 795 802,2012

[16] Tuma M, Bagadatoglu H, Boyar B, Ildan F, Iskender A, Cetinolp E, Haciyakupoglu S. Ant vs. post instrumentation in the treatment of unstable thoracolumbar fractures: A retrospective analysis of 30 cases. Turkish Neurosurgery 9: 8-15, 1999

[17] Philippe G, Marjorie S, Marc P. Isolated anterior approach or isolated post approach in the management of thoracolumbar spine fractures. The Bone and Joint $\mathbf{J}$.

[18] Stancic MF, Gregororic E, Nozica E, Penezic L. Ant decompression and fixation in the treatment of unstable burst thoracolumbar fractures. Prospective clinical trial. Croatian Medical Journal. 42 (1); 49-53, 2001

[19] Xu GJ, Li JZ, Ma JX, Zhang T, Fu X, Ma XL. Ant vs. post approach for treatment of thoracolumbar burst fractures: a meta analysis. European spine J 22: 2176- 2183, 2013

[20] Han WU, Xin WC, Yan ZZ. Comparison 3 different surgical approaches for treatment of thoracolumbar burst fractures. Chinese J of Traumatology 16(1): 31- 35, 2013

[21] Freudenberger C. Post Vs. Ant lumbar interbody fusion with ant tension band wiring retrospective analysis. Sportsmed, Huntsville, AL 358022006

[22] Erickson MA, Kuklo TR, Emans JB, Puno RM, Mc Carthy RE. Prospective analysis comparing ant vs. post approach for treatment of thoracolumbar idiopathic scoliosis. Spine 10: 53, Sept. 2009

[23] Elasawaf A. Late outcome of ant vs. post fixation for thoracolumbar fractures. International Research Journal of Basic and Clinical Studies 1(2): 22-31, 2013

[24] Muschik M. Ant vs. post double rod instrumentation for idiopathic thoracolumbar scoliosis: a comparison of results in 141 patients. German Medical Science. June 2005 